\title{
Abstract \\ Optimization of Metabolic Stability of Ligands of Serotonin Receptor 5-HT7 Using SHAP Values ${ }^{\dagger}$
}

\author{
Agnieszka Wojtuch ${ }^{1}\left(\mathbb{D}\right.$, Rafał Jankowski $^{1}{ }^{1}$ and Sabina Podlewska ${ }^{2,3, *(\mathbb{D}}$ \\ 1 Faculty of Mathematics and Computer Science, Jagiellonian University, 6 S. Lojasiewicza Street, \\ 30-348 Krakow, Poland; agnieszka.pocha@doctoral.uj.edu.pl (A.W.); rafal.jankowski@student.uj.edu.pl (R.J.) \\ 2 Maj Institute of Pharmacology Polish Academy of Sciences, Smetna Street 12, 31-343 Krakow, Poland \\ 3 Department of Technology and Biotechnology of Drugs, Jagiellonian University Medical College, \\ Medyczna Street 9, 30-688 Krakow, Poland \\ * Correspondence: smusz@if-pan.krakow.pl \\ + Presented at the 1st International Electronic Conference on Biomedicine, 1-26 June 2021; Available online: \\ https://ecb2021.sciforum.net/.
}

check for

updates

Citation: Wojtuch, A.; Jankowski, R.; Podlewska, S. Optimization of Metabolic Stability of Ligands of Serotonin Receptor 5-HT7 Using SHAP Values. Biol. Life Sci. Forum 2021, 7, 18. https://doi.org/10.3390/ ECB2021-10258

Academic Editor: Ujendra Kumar Published: 31 May 2021

Publisher's Note: MDPI stays neutral with regard to jurisdictional claims in published maps and institutional affiliations.

Copyright: (C) 2021 by the authors. Licensee MDPI, Basel, Switzerland. This article is an open access article distributed under the terms and conditions of the Creative Commons Attribution (CC BY) license (https:// creativecommons.org/licenses/by/ $4.0 /)$.

\begin{abstract}
There are numerous computational tools which support the design of new potential ligands. They assist in the evaluation of potential compound activity as well as in the optimization of compound physicochemical and pharmacokinetic properties. Nowadays, they are an indispensable element of the drug design process; both time and money can be saved with their application.
\end{abstract}

Keywords: machine learning; metabolic stability; interpretable models; G protein-coupled receptors

Nowadays, numerous computational tools are an indispensable element of the drug design process. Thanks to their application, both time and money can be saved [1-3].

In the present study, we applied a methodology based on SHAP (SHapley Additive exPlanations) values [4] to assess the metabolic stability of a series of newly designed derivatives of ligands of serotonin receptor 5-HT7. This protein is a representative of G protein-coupled receptors and constitute an important drug target, mainly for the treatment of central nervous system disorders, such as depression, cognitive disorders, anxiety, and Alzheimer's disease [5].

The aim of the application of SHAP values is to enable prediction via machine learning models and to evaluate the contributions of particular features. In our study, we used two key-based fingerprints for compound representation: MACCS keys and Klekota-Roth fingerprints. At first, we evaluated compounds with known metabolic stability from the ChEMBL database [6]. Then, using information provided by SHAP values from models constructed using known data, we selected features which are important (according to the model) for metabolic stability. This information was used for the generation of new ligands of serotonin receptor 5-HT7, with the input constituted by known ligands of this receptor gathered from the ChEMBL database. After evaluation of their 5-HT7R activity via docking, the best compounds will undergo visual inspection and will be selected for purchase and/or synthesis.

Supplementary Materials: The following are available online at https:/ /www.mdpi.com/article/10 .3390/ECB2021-10258/s1.

Funding: The study was supported by the grant OPUS 2018/31/B/NZ2/00165, financed by the National Science Centre, Poland (www.ncn.gov.pl) accessed on 22 November 2021.

Informed Consent Statement: Not applicable.

Data Availability Statement: The data are available upon request directly from the authors.

Conflicts of Interest: The authors declare no conflict of interest. 


\section{References}

1. Rao, V.S.; Srinivas, K. Modern drug discovery process: An in silico approach. J. Bioinf. Seq. Anal. 2011, 5, 89-94.

2. Reddy, A.S.; Pati, S.P.; Kumar, P.P.; Pradeep, H.N.; Sastry, G.N. Virtual screening in drug discovery-A computational perspective. Curr. Protein Pept. Sci. 2007, 4, 329-351. [CrossRef] [PubMed]

3. Mitchell, J.B.O. Machine learning methods in chemoinformatics. Wiley Interdiscip. Rev. Comput. Mol. Sci. 2014, 4, 468-481. [CrossRef] [PubMed]

4. Lundberg, S.M.; Lee, S. A Unified Approach to Interpreting Model Predictions. In Advances in Neural Information Processing Systems 30; Guyon, I., Luxburg, U.V., Bengio, S., Wallach, H., Fergus, R., Vishwanathan, S., Garnett, R., Eds.; Curran Associates Inc.: Red Hook, NY, USA, 2017; pp. 4765-4774.

5. Berger, M.; Gray, J.A.; Roth, B.L. The Expanded Biology of Serotonin. Annu. Rev. Med. 2009, 60, 355-366. [CrossRef] [PubMed]

6. Gaulton, A.; Bellis, L.J.; Bento, A.P.; Chambers, J.; Davies, M.; Hersey, A.; Light, Y.; McGlinchey, S.; Michalovich, D.; Al-Lazikani, B.; et al. ChEMBL: A large-scale bioactivity database for drug discovery. Nucleic Acids Res. 2011, 40, D1100-D1107. [CrossRef] [PubMed] 